\title{
Anlaysis of self-prescribed abortion pill: An eye opener
}

\author{
Divya Pandey ${ }^{1}$, Monika Gupta ${ }^{2 *}$, Sudha Salhan ${ }^{3}$ \\ ${ }^{1,2}$ Associate Professor, ${ }^{3}$ Professor and Unit Head, ${ }^{1-3}$ Dept. of Obstetrics and Gynaecology, ${ }^{1,2}$ Vardhman Mahavir Medical College \\ and Safdarjung Hospital, ${ }^{3}$ North DMC Medical College and Hindu Rao Hospital, Delhi, India
}

\section{Corresponding Author: Monika Gupta}

Email: drmonikagupta@hotmail.com

Received: $15^{\text {th }}$ October, 2018

Accepted: $4^{\text {th }}$ December, 2018

\begin{abstract}
Introduction: With the passage of MTP act and later its amendment, abortion was legalised in India. There are clear guidelines on who should prescribe the pills. But owing to over the counter availability of the abortion pills, its self-prescription is widely rampant.

Aims: This study aims to analyse the effects of unsupervised self-prescription of abortion pill on the maternal health.

Materials and Methods: This was an observational study done on 100 consecutive women of reproductive age group (15-45 years) seeking advice at Family planning OPD or Gynaecology emergency department of a tertiary teaching institute after self-prescription of abortion pill. The socio-demographic parameters along with source of pill procurement, gestational age at pill intake, time since pill intake, clinical presentation, medical management or surgical intervention and the final outcome was noted and analysed.

Results: The consecutive 100 women sought medical advice over only 4 months duration. Of them, $75 \%$ were multipara, $77 \%$ were urban dwellers and $83 \%$ belonged to low socio-economic status. Source of procurement was ultimately the pharmacists for all women.72\% women took pill after 7 weeks of gestation and $15 \%$ took it in second trimester. 55\% presented to the health facility within 2 weeks of pill intake. Lack of use of regular contraception was the basic reason behind pill intake for all women. Only $5 \%$ took the abortion pill with proper regime. $30 \%$ had incomplete abortion, $20 \%$ had incomplete abortion with shock, $15 \%$ had incomplete abortion with sepsis, $25 \%$ had failed abortion and $8 \%$ presented with shock and severe anemia with only $2 \%$ with complete abortion. Although $100 \%$ women had complete recovery, yet surgical intervention was needed in $76 \%$ women. Evacuation was done in $69 \%$, additional misoprostol was given in $21 \%, 7 \%$ cases underwent laparotomy for rupture ectopic while one case needed only Blood Transfusion. Blood transfusion along with surgical intervention was needed in $17 \%$ cases while broad spectrum antibiotics were needed in $15 \%$ cases of sepsis. One woman underwent hysterectomy following post-abortal sepsis with pyoperitoneum.

Conclusion: The results are an eye-opener. The over the counter availability of the abortion pill must be checked and focus should be made on counselling the women regarding the use of regular contraception practices.
\end{abstract}

Keywords: Over the counter, Self-prescription, MTP pill, Unsupervised medical abortion.

\section{Introduction}

An average of 56 million induced (safe and unsafe) abortions occurred worldwide each year between 20102014. Around 25 million unsafe abortions were estimated to have taken place worldwide each year, almost all in developing countries. Around 7 million women are admitted to hospitals every year in developing countries, as a result of unsafe abortion. ${ }^{1}$ There is one unsafe abortion for every 10 pregnancies or one abortion every 7 live births worldwide. ${ }^{2}$ Unsafe abortion is thus associated with higher maternal morbidity and mortality. The mortality is more common in the countries where the abortion is not legalized. Unsafe abortions cause $8-11 \%$ of global maternal deaths and occur predominantly in low-income and middle-income countries. ${ }^{3}$

Medical abortion as defined by WHO is the "usage of pharmacological drugs to terminate pregnancy". Medical Termination of Pregnancy (MTP Act) was passed in 1971by Indian Parliament, with the goal to regulate and ensure accessibility for safe abortion. After the passage of this Act, legal position was given to abortion in India. ${ }^{4}$ This act defined when, where and by whom it can be done. World Health Organisation (WHO) and Federation of Obstetrician and Gynaecologist Societies of India (FOGSI) have formulated guidelines for pre-abortion work up and examination for confirmation of pregnancy, correct gestational age and confirm the intra-uterine location of the pregnancy. In addition to basic lab workup it also stresses on ruling out contraindications like bleeding disorders, chronic adrenal failure and uncontrolled seizure disorder and taking detailed medical history.

The medical abortion if given after proper care selection depending on gestational age considering health status of women and in proper regimen has success rate as high as $93-98 \%{ }^{5,6}$

Inspite of this Act, availability of clear guidelines and implementation of safe and legal abortion services, unsupervised self-prescription of the abortion pill has become widely rampant. The women commonly procured the medical abortion pills directly from chemists, informal vendors and pharmacists due to over the counter availability of the drug and they received inadequate, incorrect and inaccurate information regarding the regime and the gestational age limit to use the drug. The method of medical abortion method is rather being considered as a spacing method by most women ${ }^{7}$

This prospective observational study was carried out at a tertiary teaching hospital to study the implications/consequences of self-prescription of abortion pill by pregnant women to induce abortion. 


\section{Materials and Methods}

This was an observational study on consecutive 100 women who attended family planning OPD or gynaecology emergency for seeking advice after self-prescription of medical abortion pill (MTP pill). "Self-prescription" means that the pregnant women did not seek any medical consultation from a medical practitioner and procured the drug over the counter without any prescription either by self or by relative. Women who took MTP pill under guidance of registered medical practitioner and reported to us with complications or women who underwent any surgical intervention post-MTP pill intake at any other medical centre and later reported to us were excluded from the study.

Socio-epidemiological factors like age, marital status, education status, residence and family was counselled. Obstetric history was noted, source of procurement, reason behind the pill intake, time duration since the pill intake to presentation, gestational age at time of pill consumption, the regime followed and complaint at presentation to health care facility were noted. Final outcome in the form of any medical measures and treatment or surgical intervention done was noted. Data thus compiled was entered in MS Excel sheet and data analysis done.

\section{Results}

There were 100 women over period of 4 months from January to April 2015, who reported to the emergency/Outpatient department after self-medication of abortion pill without prior medical consultation. Maximum (36\%) belonged to 25-30 years age group followed by $26 \%$, $18 \%, 10 \%, 8 \%$ and $2 \%$ belonging to the age group of $20-25$ years, $<20$ years, $30-35$ years, $35-40$ years and $>40$ years respectively (table 1). $82 \%$ were married, $4 \%$ were unmarried while $14 \%$ were divorcee. Regarding the educational status, self-medication was seen more common in low literacy females (43\%) and lower socio-economic status $(83 \%)$ while the trend was opposite for the educated women. It was also seen to be more rampant amongst urban dwellers (77\%), multigravidas (75\%) and those with previous normal vaginal deliveries $(72 \%)$. It was procured through the partner in $75 \%$ of the cases but ultimately the source of procurement was over the counter from the pharmacist.

Table 2 depicts the gestational age at pill intake, days since pill intake, and reasons for intake and the drugs taken. Only $18 \%$ women took pill at recommended less than 7 weeks, $45 \%$ women took the pill at $>9$ weeks, while $15 \%$ women consumed the pill at gestational age between 7-9 weeks and $>12$ weeks. While $30 \%$ women cited failure of emergency contraception as reason behind MTP pill intake, $25 \%, 20 \%, 21 \%$ an $4 \%$ held desire to delay first conception, conception in lactational amenorrhea, lack of regular contraception and social reasons responsible for pill consumption. Therefore ultimately it was lack of regular contraception use which was responsible.

Table 3 shows the clinical diagnosis at presentation along with the final outcome of the women under study. Although 100\% women had complete recovery, yet surgical intervention was needed in $76 \%$ women. Out of these 76 women 69 underwent D\&E while 7 underwent laparotomy for rupture ectopic. 1 patient underwent hysterectomy for post-abortal sepsis with pyoperitoneum. She had multiple blood transfusions and needed post-operative ICU care. Only $2 \%$ had complete abortion. Abortion failed to occur in 25 women, out of which 10 underwent second trimester abortion with Misoprostol while 15 had suction \& evacuation. Out of these 15 women, one women had undiagnosed molar pregnancy. $30 \%$ of the women had incomplete abortion which was managed in $63.3 \%(19 / 30)$ by surgical intervention (Dilatation \&Evacuation) and in $36.7 \%(11 / 30)$ women by medical management. $20 \%$ women came with incomplete abortion with shock and needed blood transfusion. Overall blood transfusion was needed in 26 women. 15 women needed evacuation along with broad spectrum antibiotics in view of incomplete abortion with sepsis.

Women were counselled for use of regular contraception at the time of discharge.

Table 1: Socio-Epidemiological factors of the women

\begin{tabular}{|c|c|c|c|}
\hline S. No & Epidemiological parameter & $\mathbf{N}$ & $\%$ \\
\hline \multirow[t]{7}{*}{1.} & Age & & \\
\hline & $<20$ years & 18 & 18 \\
\hline & $20-25$ years & 26 & 26 \\
\hline & 25-30 years & 36 & 36 \\
\hline & $30-35$ years & 10 & 10 \\
\hline & $35-40$ years & 8 & 8 \\
\hline & $>40$ years & 2 & 2 \\
\hline \multicolumn{2}{|l|}{ Total } & 100 & 100 \\
\hline \multirow[t]{4}{*}{2.} & Marital status & & \\
\hline & Married & 82 & 82 \\
\hline & Unmarried & 4 & 4 \\
\hline & Divorcee & 14 & 14 \\
\hline \multicolumn{2}{|l|}{ Total } & 100 & 100 \\
\hline
\end{tabular}




\begin{tabular}{|c|c|c|c|}
\hline 3. & $\begin{array}{c}\text { Educational status } \\
\qquad \text { Illiterate } \\
\text { primary } \\
\text { secondary } \\
\text { Sr. secondary } \\
\text { graduate } \\
\text { post graduate } \\
\end{array}$ & $\begin{array}{l}20 \\
23 \\
20 \\
15 \\
12 \\
10 \\
\end{array}$ & $\begin{array}{l}20 \\
23 \\
20 \\
15 \\
12 \\
10\end{array}$ \\
\hline \multicolumn{2}{|c|}{ Total } & 100 & 100 \\
\hline 4. & Residence & $\begin{array}{l}23 \\
77 \\
\end{array}$ & $\begin{array}{l}23 \\
77 \\
\end{array}$ \\
\hline \multicolumn{2}{|c|}{ Total } & 100 & 100 \\
\hline 5. & $\begin{array}{c}\text { Socio-economic status } \\
\text { Lower } \\
\text { Lower middle } \\
\text { Middle } \\
\text { Upper middle } \\
\text { Upper }\end{array}$ & $\begin{array}{c}43 \\
40 \\
16 \\
1 \\
0\end{array}$ & $\begin{array}{c}43 \\
40 \\
16 \\
1 \\
0\end{array}$ \\
\hline \multicolumn{2}{|c|}{ Total } & 100 & 100 \\
\hline 6. & Parity & $\begin{array}{l}25 \\
75 \\
\end{array}$ & $\begin{array}{l}25 \\
75 \\
\end{array}$ \\
\hline \multicolumn{2}{|c|}{ Total } & 100 & 100 \\
\hline 7. & $\begin{array}{l}\text { Previous NVD* } \\
\text { Previous } 1 \text { CS** } \\
\text { Previous } 2 \text { CS** }\end{array}$ & $\begin{array}{c}72 \\
20 \\
8 \\
\end{array}$ & $\begin{array}{c}72 \\
20 \\
8\end{array}$ \\
\hline \multicolumn{2}{|c|}{ Total } & 100 & 100 \\
\hline 8. & $\begin{array}{c}\text { Source of procurement from chemist } \\
\text { Self } \\
\text { Husband/partner } \\
\text { Relative }\end{array}$ & $\begin{array}{l}21 \\
75 \\
04\end{array}$ & $\begin{array}{l}21 \\
75 \\
04\end{array}$ \\
\hline \multicolumn{2}{|c|}{ Total } & 100 & 100 \\
\hline
\end{tabular}

*NVD: Normal vaginal delivery; **CS: Ceasarean Section

Table 2: Gestational age, time since consumption to presentation at health facility, reason and regime followed in women with self-prescription of MTP Pill.

\begin{tabular}{|l|l|c|c|}
\hline S. No & \multicolumn{1}{|c|}{ Parameters } & N & \% \\
\hline 1. & Gestational age & & \\
& $<7$ weeks & 18 & 18 \\
& $7-9$ weeks & 15 & 15 \\
& $>9$ weeks & 45 & 45 \\
& $>12$ weeks & 15 & 15 \\
\hline Total & Time (days) since pill consumption & 100 & 100 \\
\hline 2. & $<1$ week & & \\
& $1-2$ weeks & 20 & 20 \\
& $2-3$ weeks & 35 & 35 \\
& $3-4$ weeks & 25 & 25 \\
& >4 weeks & 16 & 16 \\
& & 04 & 04 \\
\hline Total & Reason for MTP pill intake & 100 & 100 \\
\hline 3. & Conception in Lactational amenorrhea & & \\
& Failure of emergency contraception & 20 & 20 \\
& Lack of regular contraception & 30 & 30 \\
& Want to delay first conception & 21 & 21 \\
& Social reason & 25 & 25 \\
\multicolumn{2}{|c|}{ Total } & 4 & 4 \\
\hline
\end{tabular}




\begin{tabular}{|l|l|c|c|}
\hline 4. & Drugs taken & & \\
& Mifepristone followed by 800 ugm Misoprost Regime & 05 & $5 \%$ \\
& Mifepristone followed by 400 ugm(2 tabs) & 10 & 10 \\
& Misoprost 800 ugm (4 tabs) & 00 & 0 \\
& Misoprost 400 ugm (2 tabs) & 37 & 37 \\
& Misoprost 200 ugm (1 tab) & 43 & 43 \\
& Mifepristone alone & 05 & 5 \\
\hline
\end{tabular}

Table 3: Clinical presentation, medical and surgical intervention and final outcome in women with self-prescription of MTP pill.

\begin{tabular}{|c|c|c|c|c|c|c|}
\hline S. No. & $\begin{array}{l}\text { Clinical diagnosis } \\
\text { /presentation }\end{array}$ & $\mathbf{N}$ & $\%$ & Measure taken & $\mathbf{N}(\%)$ & Final outcome \\
\hline 1 & Incomplete abortion & 30 & 30 & D\& E $E^{@}$ Misoprostol & $\begin{array}{l}19 \\
11\end{array}$ & Recovered completely \\
\hline 2 & $\begin{array}{l}\text { Incomplete abortion } \\
\text { with shock }\end{array}$ & 20 & 20 & $\mathrm{D} \& \mathrm{E}+\mathrm{BT}(10 / 20)^{* \#}$ & 20 & Recovered completely \\
\hline 3 & $\begin{array}{l}\text { Incomplete abortion } \\
\text { with sepsis }\end{array}$ & 15 & 15 & $\begin{array}{l}\text { Broad spectrum } \\
\text { antibiotics+D\&E } \\
+\mathrm{BT}(7 / 15)^{* *}\end{array}$ & $15(14+1 * * *)$ & Recovered completely \\
\hline 4 & Complete abortion & 2 & 2 & - & 2 & Recovered completely \\
\hline 5 & Failed abortion & 25 & 25 & $\begin{array}{c}\mathrm{S} \& \mathrm{E}^{\wedge} * * * * \\
2^{\text {nd }} \text { trimester abortion with } \\
\text { misoprostol }\end{array}$ & $\begin{array}{c}15(5+9+1 * * * *) \\
10\end{array}$ & Recovered completely \\
\hline 6 & $\begin{array}{c}\text { Shock/severe } \\
\text { anemia }\end{array}$ & 8 & 8 & $\begin{array}{c}\text { Laparotomy } \\
+\mathrm{BT}+\mathrm{U} / \mathrm{L}^{\$} \text { salpingectomy } \\
\mathrm{BT} \text { alone }\end{array}$ & $\begin{array}{l}7 \\
2 \\
\end{array}$ & Recovered completely \\
\hline \multicolumn{7}{|c|}{$\begin{array}{l}\text { *1 patient received Fresh frozen plasma and platelet transfusion along with packed cell transfusion for dilutional } \\
\text { coagulopathy } \\
\text { **BT needed in } 7 / 15 \text { patients with incomplete abortion with sepsis. } \\
\text { ***hysterectomy done for postabortal sepsis with pyoperitoneum;received multiple BT,ICU stay in post operative } \\
\text { period for } 3 \text { days(h/o instrumentation for incomplete abortion after MTP pill intake, where uterine perforation } \\
\text { occurred) } \\
\text { ****5(>9weeks); } 9(7-9 \text { weeks):1(molar pregnancy) } \\
\text { *\#BT needed in } 10 / 20 \text { patients with incomplete abortion with shock } \\
\text { @D\&E:Dilatation and Evacuation; ^S\&E:Suction and Evacuation; \# BT:Blood transfusion; } \\
\text { \$unilateral }\end{array}$} \\
\hline
\end{tabular}

\section{Discussion}

Long after the MTP Act was passed in I971, there continued to be large magnitude of unsafe abortions. The amendment in the Act (2002) legalised the use of Mifepristone and Misoprostol combined regime for early pregnancy termination. According to the Act, only an Obstetrician and Registered Medical Practitioner can prescribe the drug. Moreover patient undergoing medical abortion needs to understand the importance of proper drug regime, timely follow up and readiness and availability of medical help in case of emergency. Pre procedure clinical examination along with basic investigations along with proper counselling of the possible consequences is a must before prescribing the medication. But over the counter availability of the drug has led to self-prescription of MTP pill, a real menace to curb. The urban dwelling women with low literacy who are unable to understand the bad consequences of the unsupervised pill consumption, owing to pill's over the counter availability and easy accessibility, become easy prey.
MTP Act legalised abortion so as to reduce maternal deaths due to unsafe abortions. But still the burden of unsafe abortion in developing countries India is too high. ${ }^{8}$ Unsafe abortion include self-induced abortion or those performed by persons lacking necessary skills or in the environment without minimal medical standards or both. ${ }^{9,10}$

But still 8-11\% maternal mortality in low and middle income countries are due to unsafe abortions. It was striking to note we reached the total of 100 patients in small period of mere 4 months which gives average of 25 women per month. The figure highlights the rampant use of selfprescribed pill. According to Lancet study a, 11.5 million medial abortion per year all over which is actually an underestimate because on non-reporting of self- prescribed pills. ${ }^{11}$ Our high figure in small duration (100 in 4 months) highlights this fact.

According to a study published in Lancet (2018), in India, there were $48.1 \%$ million pregnancies for which the abortion rate was 47 abortions per 1000 women aged 15-49 years which again highlights the high magnitude of unmet 
need of contraception. 15-49 years. There were $70.1 \%$ unintended pregnancy per 1000 women aged 15-49 years and abortion rate was $47 \%$. Overall $81 \%(12.7$ million $)$ abortions were medical abortions of which 11.5 million (90\%) were medical abortion taken outside the health facilities. ${ }^{11}$

There were 100 women in our study out of which about three quarters were urban dwellers belonging to low socioeconomic status with about half having low literacy level. Similarly self-prescription was found in $51 \%$ urban population by Beant Singh et al. ${ }^{12}$ While it was more rampant in rural population i.e. $92.5 \%$ by Nivedita et al. ${ }^{13}$ This indicates, that women from all backgrounds i.e. rural/urban background practice self-prescription of abortion pill.

Source of procurement of the pill was partner in $75 \%$ cases, relative in $4 \%$ and self in $21 \%$ cases. Studies have suggested that women try to terminate an unwanted pregnancy on their own or with the advice of their partner. ${ }^{14}$ But ultimate source of procurement remains the chemists, pharmacists or the informal vendors. Similarly source of procurement was chemist in 100\% according to PK Aggarwal et al and D Anjum et al and 52.43\% according to B Singh et al. ${ }^{12,15,16}$ Getting medication from chemists results in ignorance about proper pill consumption method/regime and follow up advice. This was evident from this study where only where only $10 \%$ took the proper regime.

Only $18 \%$ women took the pill at correct gestational age. 55\% presented to us within 2 weeks of pill intake. This highlights the fact that they were completely ignorant about the regimen, follow up advice and took pill at wrong gestational age. Similarly $75 \%$ according to Nivedita et al and $60 \%$ by PK Aggarwal et al consumed pill at wrong gestational age. ${ }^{13,15}$

Though all women recovered completely but morbidity in form of shock, need of Blood transfusion was seen in $10 \%$, sepsis and need of broad spectrum antibiotics was seen in $15 \%$.Need of repeat surgical intervention was seen in form of repeat evacuation in 69\% women and laparotomy with unilateral salpingectomy in $7 \%$ and even hysterectomy for post abortal sepsis with pyoperitoneum in $1 \%$ case. The incidence of molar gestation (1 case) and ectopic pregnancy in 7 cases highlights the need of Ultrasonographic confirmation of intrauterine gestation before prescribing medical abortion in doubtful cases. Similarly Sukhwinder et al reported $41.54 \%$ in incomplete abortion, $6.54 \%$ of septicaemia and $1.15 \%$ of failed abortion. ${ }^{7}$ Similar study on consequences of self-prescription showed that $70.2 \%$ had incomplete abortion and $10.8 \%$ had failed abortion, rupture ectopic pregnancy in one and a case of one maternal death following self-prescription of abortion pills. ${ }^{17}$

With above list of complications and complexities involved in self-prescription of MTP pill, it is interpreted that our women find medical abortion as an easy option to terminate pregnancy rather than practising regular contraception. The reason is ignorance, illiteracy, lack of awareness about legal status of abortion, inhibition to seek medical advice as they want to maintain secrecy, and above all over the counter availability of drug and second trimester MTP after sex selection.

Although maternal morbidities were there but there was no maternal mortality in this study. But study by Rajal VT et al showed one mortality and laparotomy for rupture ectopic after self-prescription of the pill. ${ }^{17}$

Being a tertiary referral centre, the complications were higher, thought sample size is small, but complications like undiagnosed ectopic and molar pregnancy and sepsis needing hysterectomy post perforation in for evacuation for incomplete abortion were common. The important thing to note is that sample size of 100 women with self-prescription of MTP pill was reached within small duration of 4 months.

Thus there is high need of educating and counselling the women and to have laws and regulations to curtail the unchecked and indiscriminate distribution of MTP pill over the counter by the local chemists and pharmacists. Every effort should be taken to meet the unmet need of contraception. Almost every abortion mortality and morbidity is preventable through sexuality education, use of effective contraception, provision of safe, legal induced abortion, and timely care for complications. ${ }^{1}$

\section{Limitation}

The study was an observational study done on a small sample in a medical college hospital. So it doesn't reflect the real scenario as would have been shown by a community level study which can reveal the much broader view.

\section{Conclusion}

There is dire need of making laws for restriction of over the counter availability of Medical Abortion pills. Infact, they should be made available at and via health care facilities so as to check unfavourable outcome due to indiscriminate use of these drugs. In case of doubt of extra-uterine pregnancy on history and examination, ultrasound should be done before attempting abortion. Drug protocol should be strictly followed for maximum success. There is high need in focussing on the use of adoption of regular contraceptive practices in the women by educating and counselling them rather than making them chose abortion.

\section{Conflict of Interest: None.}

\section{References}

1. Available from https://www.who.int/news-room/detail/28-092017-worldwide-an-estimated-25-million-unsafe-abortionsoccur-each-year .(last accessed on 15-11-2018)

2. WHO, "Unsafe Abortion: Global and Regional Estimates of the Incidence of Unsafe Abortion and Associated Mortality in 2003," p.14.

3. Abortion: access and safety worldwide. Lancet. 2018;Vol 391 March 24:1121. doi: https://doi.org/10.1016/S01406736(18)30624-X.

4. Government of India. The medical termination of pregnancy act [Act no.34,1971],New Delhi. Government of India.1971.

5. Coyaji K. Early medical abortion in India: three studies and their implication for abortion services. J Am Med Women's Assoc 2000;55(3):191-4. 
6. FOGSI Focus of Medical Abortion. FOGSI-ICOG-GPCR guidelines 2011;Available from

www.issuu.com/fogsi/does/medical abortion2011.

7. Sukhwinder Kaur B, Sukhminderjit Singh B, Gagandeep Kaur G, Nirankar S, Anita S, Goraya SPS et al. Medical abortion:is it a blessing or curse for the developing nations. Srilanka $J$ Obstet Gynecol 2011;33:84-90.

8. Haddad LB, Nour NM. Unsafe Abortion: Unnecessary maternal mortality. Rev Obstet Gynecol 2009;2(2):122-6.

9. World Health Organization. Safe Abortion: technical and policy guidelines for health systems.(online)2012;1-7. Available from www.aps.who.int/iris/bitstream/10665/709141/978924154843 4eng.pdf.

10. Boland R, Katzive L. Developments in laws on induced abortion:1998-2007. Int Fam Plan Persectives 2008;34(3):11020.

11. Susheela singh, Chander Shekhar, Rajib Acharya, Ann M Moore, Melissa Stillman, Mnan R Pradhan et al. The incidence of abortion and unintended pregnancy in India 2015. Lancet Glob Health 2018;6:e111-20.

12. Beant Singh, Rama Garg, Parmeet Kaour, Balwinder Kaur, Santosh Kumari. Abuse of MTP-Pill without proper
prescription:"An Analytical study". Eur J Pharm Med Res 2017;4(8):357-361.

13. Nivedita K,F Shanthini. Is it safe to provide Abortion pills over the counter? A study on outcome following self-medication with abortion pills. J clin Diagn Res 2015;9(1):QC01-QC04.

14. Kumar R, Zavier AJ, Kalyanwala S, Jejeebhoy SJ Unsuccessful prior attempts to terminate pregnancy among women seeking first trimester abortion at registered facilities in Bihar and Jharkhand, India. J Biosoc Sci 45,2013,2015-15.

15. Pawan $\mathrm{Kr}$ Aggarwal, Lata Ratanoo. Indiscriminate use MTP pills: A women's health hazard. IOSR J dent Med Sci 2017;16(6):96-9.

16. D.Anjum, S Mehta, A Grover, AnkitaMAnn. Self medication for abortion: safety Issues. J Obstet Gynaecol India 2017;2017,67(5):382-3.

17. Rajal VT, Kruti JD, Parul TS. Self medication of abortion pill: Women's health in jeopardy. NHLJMS 2014;3:26-31.

How to cite this article: Pandey D, Gupta M, Salhan S, Anlaysis of self-prescribed abortion pill: An eye opener. Indian J Obstet Gynecol Res 2019;6(2):144-149. 